\section{Case Reports in Neurology}

Case Rep Neurol 2020;12:416-421

DOI: 10.1159/000511027

Published online: November 10, 2020

c) 2020 The Author(s)

Published by S. Karger AG, Basel

www.karger.com/crn

This article is licensed under the Creative Commons Attribution-NonCommercial 4.0 International License (CC BY-NC) (http://www.karger.com/Services/OpenAccessLicense) Usage and distribution for commercial purposes requires written permission.

\title{
A Case of Sporadic Cerebral Small Vessel Disease in an Identical Twin
}

\author{
Hilde van den Brink Nick A. Weaver Geert Jan Biessels \\ Department of Neurology and Neurosurgery, University Medical Center Utrecht Brain \\ Center, Utrecht University, Utrecht, The Netherlands
}

\section{Keywords}

Small vessel disease $\cdot$ Cognitive dysfunction $\cdot M R I \cdot I d e n t i c a l$ twin

\begin{abstract}
Sporadic cerebral small vessel disease (CSVD) is primarily attributed to heritability and vascular risk factors. Still, our understanding of the causative factors in CSVD lesion burden in the brain is far from complete. This is exemplified by this case of identical twins with remarkably similar vascular risk profiles, where one twin had developed severe CSVD on neuroimaging with cognitive deficits, while the other twin had no CSVD. This case highlights the need to search for further causes of CSVD, also beyond genetic and conventional vascular risk factors. Identification of other potential risk factors or disease mechanisms should be a priority for CSVD research to improve our understanding, prevention and treatment of this common cause of vascular brain injury with major clinical consequences.

(C) 2020 The Author(s)

Published by S. Karger AG, Basel
\end{abstract}

KARGER
Hilde van den Brink

Department of Neurology and Neurosurgery

University Medical Center Utrecht

Heidelberglaan 100, NL-3508 GA Utrecht (The Netherlands)

h.vandenbrink-2@umcutrecht.nl 


\section{Case Reports in Neurology}

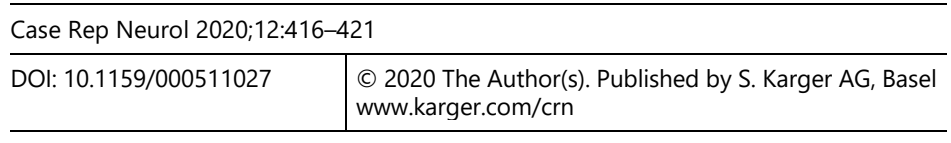

van den Brink et al.: Sporadic Cerebral Small Vessel Disease in an Identical Twin

\section{Introduction}

Cerebral small vessel disease (cSVD) is an important cause of stroke and cognitive impairment. Both single gene disorders (e.g. CADASIL) and sporadic forms of cSVD exist. Genetics also contribute to sporadic forms of CSVD, which is supported by twin and pedigree studies showing heritability rates between 52 and 78\% [1]. In addition, vascular risk factors for sporadic CSVD are well-established, but do not explain the full burden and occurrence of cSVD either $[2,3]$. Here we present a unique case of identical twins with remarkably similar vascular risk profiles, where one twin had developed severe cSVD on neuroimaging with concomitant cognitive deficits, while the other twin had no cSVD and was cognitively unimpaired.

\section{Case Report}

A 62-year-old man was referred to our memory clinic with a 2-year history of slowly progressive behavioral and cognitive changes. His family noticed that he was apathetic, had a shorter temper and was more emotional than before. Also, they noticed that his speech was notably slower and less fluent, and he had difficulty keeping focus in busy surroundings. He had a 1-year known history of hypertension, was a former smoker (1.5 pack years) and was obese (BMI: 31). Neurological examination revealed mild balance problems. Blood tests showed a slightly elevated LDL-cholesterol; no other abnormalities were found in the basic metabolic panel (including blood count, electrolytes, glucose, thyroid, vitamin $\mathrm{B}_{12}$ and liver and kidney functions). There was no family history of cardiovascular disease or dementia. Neuropsychological examination objectified most profound impairment of processing speed, executive functioning and verbal long-term memory, as well as more subtle deficiencies in word fluency and focused attention. Brain MRI showed beginning confluent white matter hyperintensities (Fazekas 2) (Fig. 1). Multiple lacunes were observed in the periventricular and deep white matter of bilateral cerebral hemispheres, and in the pons and bilateral cerebellum. Furthermore, cerebral microbleeds were seen in both sides of the putamen, both sides of the thalamus and the bilateral temporal, parietal and occipital lobes. There was mild cortical atrophy, but no hippocampal atrophy. Based on these findings, the patient was diagnosed with multi-domain mild cognitive impairment due to cerebral small vessel disease, with hypertension as a possible contributing factor.

Interestingly, the patient has an identical twin who participated in a research study as healthy volunteer, for which he underwent clinical assessment, brain MRI, and neuropsychological testing. He also had a 1-year known history of hypertension and was overweight (BMI: 29), but otherwise his medical history was unremarkable. Brain MRI of the healthy twin showed very minimal signs of cSVD for his age (Fig. 1), and cognitive testing and neurological examination were normal. Laboratory tests showed a slightly elevated LDL-cholesterol. Table 1 provides an overview of demographics and vascular risk factors of the twins. 


\section{Case Reports in Neurology}

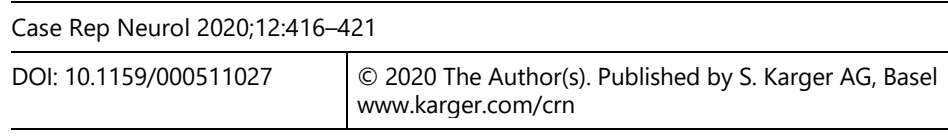

van den Brink et al.: Sporadic Cerebral Small Vessel Disease in an Identical Twin

\section{Discussion}

Here we present a case of identical twins of whom one developed severe cSVD with cognitive deficits, while the other twin showed no signs of CSVD and was cognitively unimpaired. The twins have a very similar vascular risk factor profile, with the only exception that the patient had a brief history of smoking and needed more antihypertensive medication to control blood pressure than his healthy brother.

Based on current knowledge it is hard to find a complete explanation for the discordant cSVD severity and consequent cognitive deficits in this pair of identical twins. We do not have genetic data available, but because the brothers are identical twins, they should have a highly similar genome. It is therefore unlikely that genetic differences would fully explain the very different phenotypes. The discordant phenotype might be explained by different gene expression through epigenetics. It is, however, unknown what (environmental) factor would have triggered such epigenetic processes.

In addition, vascular risk factors are well known to contribute to sporadic cSVD, with hypertension recognized as a key risk factor $[2,4]$. Nevertheless, the minimal difference in blood pressure controllability (i.e., amount of medication needed) and the brief history of smoking of the patient seem insufficient to explain the large difference in cSVD severity and cognitive outcome. This is supported by earlier work that concluded that vascular risk factors together only explain a very limited part of variance (2\%) in cSVD markers on MRI [3]. Current knowledge thus seems insufficient to identify all relevant risk factors in this case of sporadic cSVD.

In accordance with the current views in the cSVD research field [5], this case emphasizes that known causes for cSVD seem to insufficiently explain cSVD occurrence and consequent cognitive impairment. This case highlights that we are likely missing essential information on other potential risk factors or disease mechanisms that contribute to sporadic cSVD. Given the important impact of cSVD at the population level, through stroke, dementia and other forms of functional loss, it is clear that this knowledge gap needs to be addressed, in order to improve prevention and treatment. cSVD research has thus far often been rather descriptive, using mainly downstream markers of tissue injury to better understand the disease. There is clearly a need to identify specific modifiable molecular and cellular pathways that are fundamental to cSVD. These include molecular targets identified through rare cases of monogenetic forms of SVDs that may also be relevant to sporadic forms, but also processes like endothelial dysfunction, inflammation and increased blood brain barrier leakage [5]. We also need more specific cSVD biomarkers reflecting the condition of the small vessels themselves. These would be of value in future etiological studies but can also be used as outcome measure to provide proof of efficacy for novel treatments targeting the small vessels. Such approaches are currently being tested in the H2020 program “SVDs@target"' (https://www.svds-at-target.eu/). This does not take away that treatment of known (vascular) risk factors according to current guidelines $[6,7]$ is of utmost importance.

\section{Acknowledgement}

The authors would like to thank Paul J. Hop for his helpful review of the manuscript. 


\section{Case Reports in Neurology}

\begin{tabular}{l|l} 
Case Rep Neurol 2020;12:416-421 \\
\hline DOI: 10.1159/000511027 & $\begin{array}{l}\text { (c) 2020 The Author(s). Published by S. Karger AG, Basel } \\
\text { www.karger.com/crn }\end{array}$ \\
\hline
\end{tabular}

van den Brink et al.: Sporadic Cerebral Small Vessel Disease in an Identical Twin

\section{Statement of Ethics}

Both subjects participated in a research study for which the medical ethics review committee of the University Medical Centre Utrecht has approved the protocol and use of human subjects (under reference number NL62090.041.17). This study is conducted in accordance with the Declaration of Helsinki. Written informed consent for participation in the research study was obtained from the subjects and is stored in our hospital. The subjects also provided written informed consent to publish this report about their case.

\section{Conflict of Interest Statement}

Hilde van den Brink and Nick A. Weaver have no conflicts of interest to declare. Geert Jan Biessels consults for and receives research support from Boehringer Ingelheim. All financial compensation for these services is transferred to his employer, the UMC Utrecht.

\section{Funding Sources}

Supported by SVDs@target that has received funding from the European Union's Horizon 2020 research and innovative program under grant agreement No. 666881.

\section{Author Contributions}

Hilde van den Brink is responsible for the acquisition of the data and drafted the manuscript for intellectual content. Nick A. Weaver drafted the manuscript for intellectual content. Geert Jan Biessels revised the manuscript for intellectual content.

\section{References}

1 Choi JC. Genetics of cerebral small vessel disease. J Stroke. 2015 Jan;17(1):7-16.

2 Wardlaw JM, Smith C, Dichgans M. Mechanisms of sporadic cerebral small vessel disease: insights from neuroimaging. Lancet Neurol. 2013 May;12(5):483-97.

3 Wardlaw JM, Allerhand M, Doubal FN, Valdes Hernandez M, Morris Z, Gow AJ, et al. Vascular risk factors, large-artery atheroma, and brain white matter hyperintensities. Neurology. 2014 Apr;82(15):1331-8.

4 Staals J, Makin SD, Doubal FN, Dennis MS, Wardlaw JM. Stroke subtype, vascular risk factors, and total MRI brain small-vessel disease burden. Neurology. 2014 Sep;83(14):1228-34.

5 Wardlaw JM, Smith C, Dichgans M. Small vessel disease: mechanisms and clinical implications. Lancet Neurol. 2019 Jul;18(7):684-96.

6 Smith EE, Saposnik G, Biessels GJ, Doubal FN, Fornage M, Gorelick PB, et al.; American Heart Association Stroke Council; Council on Cardiovascular Radiology and Intervention; Council on Functional Genomics and Translational Biology; and Council on Hypertension. Prevention of Stroke in Patients With Silent Cerebrovascular Disease: A Scientific Statement for Healthcare Professionals From the American Heart Association/American Stroke Association. Stroke. 2017 Feb;48(2):e44-71.

7 Gorelick PB, Scuteri A, Black SE, Decarli C, Greenberg SM, Iadecola C, et al.; American Heart Association Stroke Council, Council on Epidemiology and Prevention, Council on Cardiovascular Nursing, Council on Cardiovascular Radiology and Intervention, and Council on Cardiovascular Surgery and Anesthesia. Vascular 


\section{Case Reports in Neurology}

\begin{tabular}{l|l}
\hline Case Rep Neurol 2020;12:416-421 \\
\hline DOI: 10.1159/000511027 & $\begin{array}{l}\text { @ 2020 The Author(s). Published by S. Karger AG, Basel } \\
\text { www.karger.com/crn }\end{array}$ \\
\hline
\end{tabular}

van den Brink et al.: Sporadic Cerebral Small Vessel Disease in an Identical Twin

contributions to cognitive impairment and dementia: a statement for healthcare professionals from the american heart association/american stroke association. Stroke. 2011 Sep;42(9):2672-713.

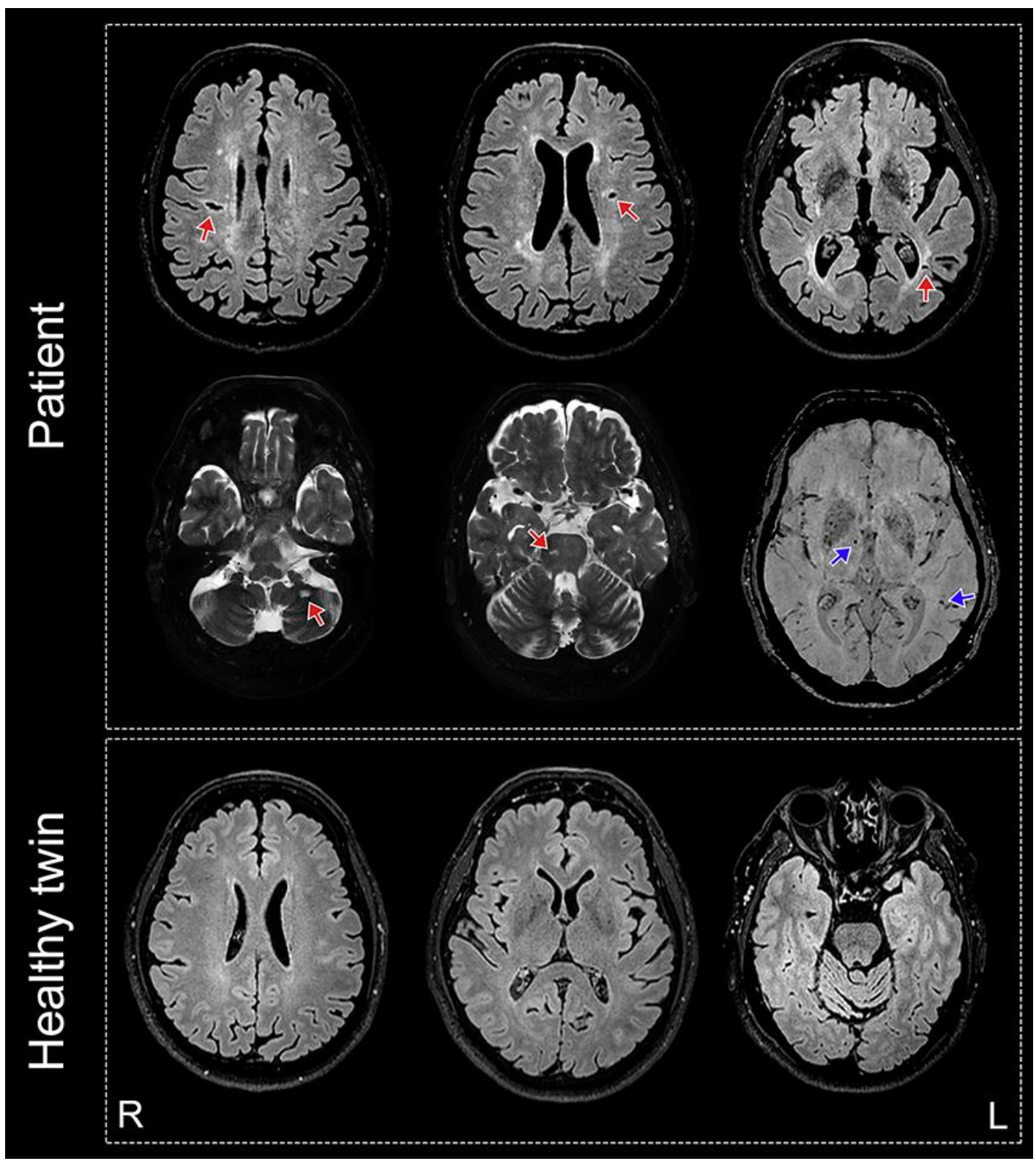

Fig. 1. Brain MRI for the patient and healthy twin (age 62 years). Representative axial slices are shown. Fluid-attenuated inversion recovery sequences are shown for the patient (top row) and healthy twin (bottom row), and T2-weighted (middle row, left and center image) and susceptibility-weighted sequences (middle row, right image) are shown for the patient. Red arrows indicate lacunar infarcts and blue arrows indicate cerebral microbleeds. R, right; L, left. 
Case Reports in

Neurology

\begin{tabular}{l|l}
\hline Case Rep Neurol 2020;12:416-421 \\
\hline DOI: 10.1159/000511027 & $\begin{array}{l}\text { c } 2020 \text { The Author(s). Published by S. Karger AG, Basel } \\
\text { www.karger.com/crn }\end{array}$ \\
\hline
\end{tabular}

van den Brink et al.: Sporadic Cerebral Small Vessel Disease in an Identical Twin

Table 1. Demographics, vascular risk factors and medication use for the patient and his identical healthy twin

\begin{tabular}{|c|c|c|}
\hline & Patient & Healthy twin \\
\hline \multicolumn{3}{|l|}{ Demographics } \\
\hline Education & Higher secondary education & Higher secondary education \\
\hline Profession & Industrial buyer & Financial controller \\
\hline \multicolumn{3}{|l|}{ Vascular risk factors } \\
\hline Hypertension & Yes, since 1 year & Yes, since 1 year \\
\hline Current blood pressure & 123/81 mm Hg & 136/92 mm Hg \\
\hline Hypercholesterolemia & LDL-cholesterol 3.8 & LDL-cholesterol 3.9 \\
\hline Diabetes mellitus & No & No \\
\hline Smoking & Former, 1.5 pack years & Never \\
\hline Alcohol & Yes, 1-2 per week & Yes, 1-2 per week \\
\hline BMI & 31 & 29 \\
\hline \multirow[t]{3}{*}{ Medication } & Lisinopril $10 \mathrm{mg}$ & Lisinopril $10 \mathrm{mg}$ \\
\hline & Amlodipine $5 \mathrm{mg}$ & \\
\hline & Hydrochloorthiazide $12.5 \mathrm{mg}$ & \\
\hline
\end{tabular}

